\title{
Income and population dynamics in deprived neighbourhoods: measuring the poverty turnover rate using administrative data
}

\begin{abstract}
Many studies of neighbourhood deprivation have confirmed that there is more continuity than change in the geography of deprivation. This stable geography can lead to an unwarranted inference that the households living on low incomes in these areas comprise a relatively static population. This paper develops the use of administrative data for the longitudinal observation of low income families in small areas, which is underdeveloped despite the widespread use of administrative data in the cross-sectional measurement of neighbourhood deprivation. An empirical measure of local poverty dynamics - the poverty turnover rate $\hat{a} €$ " is introduced, and created for small areas using housing benefit data for the city of Oxford between 2010 and 2014. A high turnover of poor families is observed and the poverty turnover rate is able to identify small areas with higher and lower turnover rates than the average for the city. The high turnover rates discovered in this study suggest that in this city it is primarily the flows of people in and out of the area, and in and out of low income, that maintains the concentration of poor families, rather than a static population of poor families. This approach can be used to provide a richer understanding of the population and income dynamics that underpin stability and change in the geography of poverty, of use to regeneration policy and the academic studies of gentrification, health inequalities and neighbourhood effects.
\end{abstract}

\section{Introduction}

"Because we have been in this position for the last five years anyway it's going to be a case of people thinking 'Oh well, what has changed?' We just get on it with it."

Secretary of the Jaywick Forum, quoted in the East Anglian Daily Times, 30 September 2015 (Lodge 2015) 
In September 2015 the seaside resort of Jaywick became the focus of UK national news attention after being labelled the most deprived area of the country according to the English Indices of Deprivation. Most media coverage highlighted the fact that Jaywick had also been identified as the most deprived area five years earlier, in the 2010 Indices of Deprivation. In August 2016 Paisley, a town seven miles west of Glasgow, was identified as home to the most deprived Scottish neighbourhood according to the Scottish Index of Multiple Deprivation - an unwanted title that had also been bestowed upon it in 2012 .

This relatively unchanging geography of deprivation is not limited to those few areas identified as being the very most deprived. Up and down the UK, in small coastal towns and major cities, the observation in most places is that there is more continuity than change in the geography of deprivation and poverty. This stable geography, confirmed in a variety of studies, can lead to an unwarranted inference that the families who experience low income within a given area comprise a static group, despite national longitudinal evidence showing high turnover amongst poor families (section 2).

This paper develops an empirical measure of turnover amongst poor families in small neighbourhood areas - the poverty turnover rate - using administrative data from housing benefit claims (section 3). The city of Oxford is used as a case study area between 2010 and 2014. The measure is strongly correlated with the official cross-sectional small area estimates and performs particularly well for working age families (section 4.1).

Far from finding a large static population of poor families, the housing benefit measure reveals a high flow of families. The flows observed are a combination of two processes: residential mobility in and out of the city, and income mobility in and out of low income. In 2010 there were 8,820 families living in rented homes on incomes below the poverty line in Oxford and, in line with post-recession national trends, this number fell to 8,190 families in 2014 (section 4.2). However, only 4,900 of these 8,190 families (60\%) had been among the population of poor Oxford families four years earlier. The remaining 3,290 families (40\%) had become new members of the population of poor Oxford families - through entering poverty and/or by moving in to the area. A higher probability of leaving the population of poor Oxford families was associated with living in a privately rented home, claiming a work-related welfare benefit, being a lone parent and having an adult in employment.

The poverty turnover rate identifies neighbourhood areas with higher and lower turnover rates than 


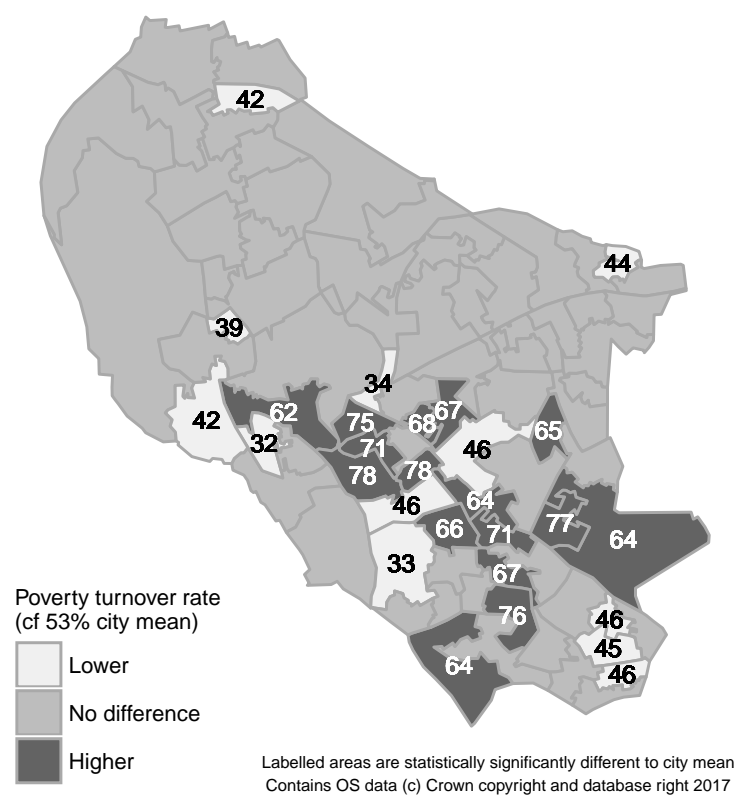

Figure 1: Poverty turnover rate by LSOA (per cent) 2010-2014, Oxford

the average for the city (section 4.3). This is primarily due to the differing composition of families by tenure within those areas - high turnover rate areas having high concentrations of private rented housing.

The high poverty turnover rates discovered in this study illustrate that it is the flows of people in and out of an area, and in and out of low income, that maintains the concentration of poor families in this city, rather than a static population of stubbornly poor families. However the dominant cause of these flows - residential mobility or income mobility - cannot be disentangled (section 5). To the extent that these flows are indicative of high levels of poverty exit - as highlighted by Jenkins (2011) - it reminds anti-poverty policymakers to focus as much on poverty (re-)entry as focusing on getting people out of poverty. To the extent that it reflects high levels of residential mobility amongst persistently poor families, it points to the need to improve security of housing tenure to facilitate the development and maintenance of social networks.

The approach outlined in this paper develops the potential for using administrative data in the longitudinal measurement of poverty and deprivation at small, neighbourhood level. This potential has thus far been under-realised, despite the established use of administrative data for cross-sectional measures. The approach can be used to provide a richer understanding of the population and income 
dynamics that underpin stability and change in the geography of poverty, of use to regeneration policy and the academic studies of gentrification, health inequalities and neighbourhood effects. As a complement to the existing small area poverty estimates, it could be used by funding agencies to target area-based funding and initiatives at areas of high poverty persistence where currently poor families may be more likely to suffer long-term material deprivation.

\section{Motivation: why study poverty dynamics in small areas?}

The study of poverty dynamics is about understanding the experience of income poverty over time. Many measures of poverty are cross-sectional - they count the number of people living on an income below a poverty line at a given point in time. Studies of poverty dynamics take time into account, such as the length of time a family has been poor for. Policymakers might be less concerned if poverty is only a short-term experience which is more easily coped with; more concerned if poverty is persistent within families over a long period.

Neighbourhood-level cross-sectional indicators of poverty are widely used in UK social policy and research. Three broad classes of approach have emerged: proxy indicators based upon decennial Census socio-economic data (Carstairs and Morris 1990; Williamson 2015); proxy indicators based upon receipt of means-tested benefits (Gambaro et al. 2015; T. Smith et al. 2015a); and small area estimation via regression models or micro-simulation (Anderson 2007; Dorling et al. 2007; Fry 2011). UK government bodies now regularly produce two measures of income poverty for neighbourhood areas in England: the income domain of the English Indices of Deprivation (T. Smith et al. 2015a), with similar version for Scotland, Wales and Northern Ireland; and the Children in Low Income Families Local Measure (HMRC 2014).

Cross-sectional estimates of the population experiencing poverty in a given neighbourhood at a certain point in time reveal that the geography of poverty is relatively stable - the poorest areas at one time point tend to be the poorest areas at another (Gambaro et al. 2015; T. Smith et al. 2015b; Tunstall 2016). This can lead to an inference that within a given neighbourhood the population who experience poverty is a static group. National evidence shows that in fact there is a high degree of turnover in the population of poor families (DWP 2010; Office for National Statistics 2016a). Summarising UK poverty dynamics over the period 1991-2006, Jenkins (2011) shows that every 
year around $40 \%$ of poor people left poverty while around $10 \%$ of non-poor people entered poverty.

Whilst there is good national evidence, there is little or no subnational evidence illustrating this phenomenon. The argument for local evidence is two-fold. First, national evidence is not always trusted by local policymakers, who can believe (rightly or wrongly) their area is idiosyncratic. Second, at a subnational level the turnover in the population of poor families is a function of two processes - the degree of income mobility in and out of poverty, and the degree of residential mobility in and out of the area. Residential mobility is a relatively common experience, with around $11 \%$ of people moving each year (Robson et al. 2009). Mobility rates are strongly linked to position in the life course, with young adults most likely to move home (Champion et al. 1998) but there is little evidence that population turnover varies by area deprivation (Bailey and Livingston 2007).

The notion of a static local population of poor families is problematic first because it supports the myth of a "welfare dependent underclass" (Hills 2014a) who are persistently out of work and claiming state support. This can stigmatise those who claim welfare support and those who live in predominantly low income areas. It may also contribute to decreasing levels of support for a state welfare safety net.

Second, stable levels of poverty in an area over time can be represented to local policy makers as evidence of a stubborn, static population of poor families who require intervention to raise their incomes from employment. The degree to which this is true is likely to vary between neighbourhoods. Information about the population and income dynamics which maintain and change the characteristics of areas is generally not available to policy makers; if made available, it could be used to tailor policy interventions to places according to the dynamics at play (Addison et al. 2009; Bossert et al. 2012).

Third, cross-sectional poverty measures do not capture the depth of material deprivation in an area that may result from poverty persistence within families. Cross-sectional indicators of poverty do not correlate directly with indicators of material deprivation (Belfield et al. 2016, pp74-76), partly because families experiencing poverty for a short spell can use savings or other assets to maintain their living standards (Gordon 2006: p41). Two areas with the same level of cross-sectional poverty may have very different levels of material deprivation if one has high levels of poverty persistence, the other high levels of turnover. A considerable amount of funding has been directed using the English Indices of Deprivation and its counterparts, and this may be better prioritised with a 
complementary measure of poverty dynamics.

Although increasing attention is now being paid to poverty dynamics (DWP 2010; Jenkins 2011; N. Smith and Middleton 2007), its study within small neighbourhood areas is not well advanced despite the potential of administrative data to support longitudinal studies (G. Smith et al. 2004). This paper is inspired in large part by Barnes et al. (2011), a rare small area longitudinal study which used administrative data to explore the dynamics of unemployment in high-worklessness neighbourhoods. Conducted over the period 2004-2007, this study found that there was little evidence to support the hypothesis that persistently high levels of worklessness observed in some neighbourhood areas were caused by the propensity for people gaining employment to leave these areas. Approximately one-third of people gaining employment left the area, the remainder staying. It also found that flows of workless families in and out of these areas were a significant factor at around $25 \%$ of all families over the period, larger than the flow of $15 \%$ who entered employment. Noble et al. (1998), another study in the limited canon, tracked claims for Income Support (a low income cash transfer) amongst lone parents claiming housing benefit in one town over 1993 to 1997, finding that just $20 \%$ had uninterrupted claims over a four year period. However, recurrent spells of claiming Income Support meant that $43 \%$ of lone parents who were claiming in 1993 were also claiming in 1997. Half of lone parents in the study had Income Support claims lasting for two years or less.

This paper complements the existing evidence by using poverty status as an outcome variable at neighbourhood level, providing substantive findings for one city as well as outlining a method that could be applied in other areas using similar data.

\section{Method: Using administrative data to measure local poverty dynamics}

\subsection{Aims of this study}

This paper explores the construction and utility of a dynamic local poverty measure, as a complement to the cross-sectional, static measures that are currently available. It utilises administrative data

about low income families claiming support for paying their housing costs (housing benefit). The 
principal research questions are:

- Can housing benefit data be used to construct a small area indicator of income poverty that is consistent with official estimates?

- How much turnover is there in the population of poor families claiming housing benefit? How do turnover rates differ by family type?

- At sub-city level, is there variation between neighbourhoods in the rate of turnover among poor families?

The subsections of section 4 answer these questions in turn. This study does not aim to generalise the substantive findings for Oxford to other English cities - rather the aim is to develop a method that could be used to answer these questions in other localities, given access to the same or similar data. The analysis in this paper has been coded in the statistical language $\mathrm{R}$ ( $\mathrm{R}$ Core Team 2016) and has been made available so that researchers may reproduce the analysis using their own data ${ }^{1}$. It is also hoped that in future this method may be utilised on a dataset with national coverage.

\subsection{Data: housing benefit claims in Oxford city}

The study of poverty dynamics requires a panel dataset that records income for individual families, linked longitudinally over several time points. This paper uses housing benefit data for the city of Oxford; the study area is briefly described in section 3.4. Housing benefit is a cash transfer (or 'benefit') paid in the UK to low income families in order to subsidise their housing costs. Approximately one-fifth of all UK families claim housing benefit, which amounts to $76 \%$ of those who are eligible to claim it (DWP 2016a).

A successful claim for housing benefit is subject to certain eligibility criteria, which restricts the coverage of this dataset. First, it is payable only to families who rent their home, either from a private landlord or in the social sector. It therefore excludes families who own their home, who in the UK comprise around half of poor families (DWP 2016b).

Second, families must have an income low enough to be deemed to require support with housing costs. Families claiming one of four means-tested benefits are automatically eligible for housing benefit and receive the maximum eligible amount. These are referred to as 'passport' benefits and

\footnotetext{
${ }^{1}$ The code is available at https://github.com/mfransham/2017-09-SHBE-analysis.
} 
include: income-based Jobseeker's Allowance (JSA), paid to working-age unemployed individuals; income-based Employment and Support Allowance (ESA), paid to working age people unable to work though illness or disability; Income Support (IS), paid to carers and lone parents with young children; and Pension Credit Guarantee (PC), paid to low income pensionable-age people. If families are not claiming one of these benefits the eligible income threshold depends upon age, family composition and whether there are family members with a disability. Some income sources, such as child maintenance paid by a former partner, are disregarded. Third, there are restrictions on assets. Families are ineligible for housing benefit if they have assets or property valued at over $£ 16,000$.

During the period of this study housing benefit reforms have reduced the maximum amount that families can claim towards their housing costs. In April 2008 the amount that could be claimed for privately rented housing was restricted to the median rent in the local housing market; in April 2011 this was reduced to the 30th centile rent. In April 2013 the 'bedroom tax' was introduced for social housing tenants. Those deemed to be underoccupying their home have their housing benefit reduced by $14 \%$ if they have one spare room or $25 \%$ if they have two or more spare rooms. At the same time the 'benefit cap' restricted the total amount of state welfare benefits that could be claimed by a workless family to $£ 26,000$ per year, which was reduced to $£ 20,000$ in November 2016 . Any payments over the threshold are clawed back by reducing the amount of housing benefit paid.

The study period has also witnessed an increase in welfare conditionality, the requirement for claimants of state support to meet certain behavioural conditions (Webster 2016). For claimants of JSA (unemployment benefit) this may include attending appointments with advisors or completing a certain number of job applications. Sanctions can be applied if these conditions are not met, which can include a complete withdrawal of JSA for up to three years. These sanctions do not apply to housing benefit however.

The significant gaps in the coverage of the housing benefit dataset are therefore poor families who own their home, and poor families who rent but do not claim the housing benefit for which they are eligible. The exclusion of home-owners disproportionately affects the pensionable age poor, $85 \%$ of whom owned their own home in 2014/15, compared to around 40\% of those at younger ages (DWP 2016b). It is therefore to be expected that a poverty indicator based upon housing benefit data will cover significantly fewer poor older people than proxy measures based on administrative data includes home-owners (see section 4.1). 
Analysis of take-up rates for housing benefit (DWP 2016a) shows that claim rates are lower for working age people $(76 \%)$ than pensioners (85\%), lower amongst private renters $(66 \%)$ than social renters $(88 \%)$, lower for couples with children (61\%) than other working age family types (80\%), and lower for in-work (55\%) than out-of-work ( 95\%) families. Analysis by Jenkins (2011) of annual poverty exit rates suggests that working age people, couples with children and families in work would have high rates of poverty exit; their lower representation in the housing benefit dataset may therefore lead to higher observed levels of poverty persistence than would be the case otherwise.

The coverage of this dataset means that once a family ceases their housing benefit claim no further observations of income or residential location are available. It is also geographically limited - families who move out of the local authority area are no longer included in the data. Further discussion of these limitations and their implications for interpreting the findings is contained in section 5 .

These limitations notwithstanding, housing benefit data has several advantages over other administrative sources of family income. It contains all the information about family income and composition that are used in official small area estimates of poverty in a single dataset, rather than needing to link several datasets. Being related to support for housing, the address data is near complete. The accuracy and completeness of addresses is often a significant shortcoming of UK administrative data sources - for example, Barnes et al. (2011) found that $40 \%$ of address data in their source was missing for people who found employment. Housing benefit data is available via local authorities for relatively small geographic areas, making small case studies such as this one viable. Although its coverage is limited to low income families who rent their homes and claim state support for their housing costs, this is an interesting group of study in itself, given the higher risk of poverty and precarity amongst renting families.

Access to housing benefit data for July 2010, August 2012 and July 2014 was secured from Oxford City Council. A four-year period of study was chosen because this is the typical interval between releases of the official Indices of Deprivation dataset.

Access to the data was subject to institutional research ethics approval and a data sharing agreement with the local authority. Names were pseudonymised to remove identifying information whilst preserving the ability to link datasets over time. After matching procedures were completed (section 3.8), dates of birth were replaced with age categories and addresses replaced with 2011 Lower Super Output Area (LSOA) codes by linking postcodes to the National Statistics Postcode Directory (see 
section 3.3).

\subsection{Spatial resolution}

The analysis in this paper is conducted at two spatial scales - Oxford local authority area and its constituent neighbourhoods, for which Lower Layer Super Output Areas are used as proxy.

Oxford local authority (LA) is one of 326 local authority districts in England. LAs are elected bodies responsible for delivering a varying set of public services within their geographical area including housing, leisure services, public health, waste collection and economic development. They are also responsible for administering certain state welfare benefits including housing benefit, the data used in this study.

Lower Layer Super Output Areas (LSOAs) are the neighbourhood unit of analysis in this study. These are small areas constructed for the production of statistical outputs, designed to contain an average population of 1,500 residents and to be as socially homogenous as possible. These are broadly neighbourhood-sized in scale, though they do not necessarily conform to natural neighbourhoods as they may be understood by residents. They have been chosen for comparability with the existing official statistics, which are also produced at LSOA level, and because addresses are easily mapped in to LSOAs by means of the National Statistics Postcode Directory. There are 83 LSOAs in Oxford.

\subsection{The study area}

Oxford is a city in southern England, UK, with a resident population of 160,000. It is well known around the world for the University of Oxford's 'dreaming spires' and honey-coloured stone buildings, but it has a parallel history as a car manufacturing town. Oxford's motor industry began in 1913 and at its height employed 30,000 people, now reduced to a workforce of 4,000. Oxford has three large peripheral suburbs built as social housing estates, which feature among the $20 \%$ most deprived neighbourhoods in England according to the English Indices of Deprivation. Oxford has a child poverty rate which is similar to the England average, but in these outlying areas up to $45 \%$ of children grow up in poor families (Oxford City Council 2015). Housing in the city is notoriously

expensive, Oxford being frequently named the least affordable city in the UK (Centre for Cities 2017). 


\subsection{Unit of analysis}

Income poverty is analysed at the family level, the same level at which housing benefit eligibility is assessed. The terminology employed by official statistics is used here to distinguish between households and families. A family consists of a single person or a couple living in a relationship, plus any dependent children. A household is a group of people living at the same address, sharing living or cooking facilities. A household may therefore consist of one or more families. The term benefit unit is also sometimes used when referring to claimants of welfare benefits - it has the same definition as family, which is the term used in this study.

In this analysis pensionable age families are defined as those where all adults are aged 65 years or over. Families were defined as 'parents' where there were one or more dependent children in the family; dependent children are those aged under 16 years or aged under 20 years and in full-time education.

\subsection{Calculating the income poverty indicator}

The analysis uses the standard definition of income poverty - families whose equivalised income is below $60 \%$ of the national median income, calculated here before housing costs. This is the definition used by existing official estimates (see section 4.1), employed to ensure comparability. Section 5.2 considers how these findings might differ if poverty were measured after housing costs. Administrative data from benefit claims does not contain information about all family income sources - it includes only those which are required to assess eligibility for the benefits in question. As a consequence, the Department for Work \& Pensions creates a bespoke poverty line for the official small area estimates which takes into account only those income sources used for the calculation of benefit eligibility (see HMRC (2014) for further details). This poverty line is updated each year. The housing dataset contains these same income sources, so the same bespoke poverty line is used in this study.

As in the official estimates, any family claiming one of the four 'passport' benefits (section 3.2) was assumed to have an income below the poverty line. Families not claiming one of these benefits had their total taxable income summed and then equivalised according to the OECD scale in order to account for the larger incomes required by larger families (see below). Those families whose income 
fell below the specially-constructed poverty line were identified as being poor families in that year.

In order to identify transitions of family incomes below to just above the poverty line, a 'near poor' status is also used in section 4.2. This is defined as families who have incomes between $60 \%$ and $80 \%$ of national median income.

\subsection{Income equivalisation}

Family incomes are equivalised in order to take account of the greater resources that larger families require to meet their needs. As with the official estimates, this study uses the OECD modified equivalence scale which takes a family of two adults as its reference point. Under this scheme each family has an equivalence score calculated by assigning contributing values to each member of the family. The first adult counts as 0.67; any subsequent adults or children aged 14 and above count 0.33 each; and children under 14 years count as 0.2 each. Thus a family of two adults and two children under 10 years would have an equivalence score of $0.67+0.33+0.2+0.2=1.4$. The family's actual income is divided by the equivalence score to arrive at the family's equivalised income.

\subsection{Matching procedures}

Family records were linked over time in order to track changes in poverty status. The variables available for matching in the housing benefit dataset were limited to housing benefit claim number, National Insurance (NI) number, name and date of birth. NI number, name and date of birth were available for the main claimant and, where applicable, their partner. Records were linked at family level using deterministic matching methods using (in order of application): housing benefit claim number; claimant NI number; surname and date of birth; and claimant NI number to partner NI number (and vice-versa). A series of matching methods were employed so that families who changed their housing benefit claim number would still be linked in subsequent time periods. As an example of matching rates, 9,390 of the 12,240 records in the 2010 file $(77 \%)$ were matched to records in the 2012 file. The majority of matches were made on the housing benefit claim number. 


\section{Findings}

The following three subsections address the three main research questions set out in section 3.1. Section 4.1 compares the housing benefit estimates of income poverty to the two available official estimates, in terms of coverage and spatial distribution. Section 4.2 quantifies the degree of turnover among poor families by type over the period 2010 to 2014, and conducts exploratory regression analysis to identify the factors that predict leaving the population of poor Oxford housing benefit families. Section 4.3 explores whether poverty turnover rates differ between neighbourhoods within the city.

Analysis was carried out in R version 3.4 .3 (2017-11-30) (R Core Team 2016) with particular use of packages dplyr (Wickham and Francois 2016), ggplot2 (Wickham and Chang 2016) and riverplot (Weiner 2015). Numbers reported in text and tables have been rounded to the nearest 10 in order to guard against statistical disclosure. Any percentages reported are based upon the underlying unrounded numbers.

\subsection{The housing benefit indicator of poverty is strongly correlated with official small area estimates}

This section validates the housing benefit poverty indicator, finding it strongly correlates with the two existing official estimates for areas of England. First, the estimated number of people living on low incomes is compared between the housing benefit indicator and the English Indices of Deprivation; second, this is compared over the period 2010-2014 with the Children in Low Income Families measure for children only; third, the spatial distribution of the housing benefit and Indices of Deprivation measures is compared. Before these analyses are presented, the existing official estimates are briefly described.

The existing official proxy indicators of income poverty in small areas are the income domain of the English Indices of Deprivation (T. Smith et al. 2015a) and the Children in Low Income Families Local Measure (HMRC 2014). The two measures use very similar methods and this study replicates them with housing benefit data (section 3.6). In the Indices of Deprivation income domain (IDID), the number of people living in poverty is estimated as the sum of adults and children in families in which a claim is made for either (i) one of the four 'passport' benefits, or (ii) in-work tax credits, 
Table 1: Estimated numbers in poverty August 2012 by age group, Oxford - Indices of Deprivation income domain (IDID) compared to housing benefit (HB)

\begin{tabular}{l|r|r|r}
\hline Age group & IDID & HB & Coverage (\%) \\
\hline Children & 5,220 & 5,050 & 96.7 \\
\hline Working age & 8,440 & 7,560 & 89.6 \\
\hline Pensioners & 3,330 & 2,100 & 63.2 \\
\hline All ages & 16,990 & 14,710 & 86.6 \\
\hline
\end{tabular}

where equivalised income is below $60 \%$ of national median income. It is published at LSOA level for all ages, broken down into children and older people (60 years plus). As a result the rate for working age people (16 to 59 years) can also be calculated. The 2015 English Indices of Deprivation refers to a time point of August 2012; earlier iterations cover August 2005 and August 2008, and so fall outside the study period considered here. The Children in Low Income Families Local Measure (CLIF) uses a very similar method to estimate the number of children in families with incomes below the poverty line. This measure has been published annually covering the period 2006 to 2014 with an August reference point (HMRC 2014).

Both the official estimates and the housing benefit indicator underestimate the population of poor families because they do not include those poor families who are eligible for but not claiming means-tested benefits or tax credits. There may also be some income poor families who are ineligible for these benefits - for example, those with low incomes but savings above the allowed threshold. However it is expected that these two official estimates would be better proxy measures of income poverty than the housing benefit indicator as they cover owner-occupiers as well as renters. As noted in section 3.2 the largest impact will be upon the coverage of poor pensionable age people as they are most likely to be owner-occupiers.

Table 1 shows the estimated number of people living income poor families in Oxford in August 2012 according to the IDID and HB indicators, by age group. As expected, the coverage of the HB indicator compared to IDID is lowest for pensionable age people at $63.2 \%$. Given that national figures suggest around $40 \%$ of working age poor families live as owner-occupiers, the coverage of the HB indicator for children (96.7\%) and working age people $(89.6 \%)$ is surprisingly high.

As expected, the HB estimates for children in poor families in 2010, 2012 and 2014 are lower than the official estimates from the CLIF measure (Figure 2). However the two estimates are consistently related, showing a fall over time; the coverage of the HB indicator relative to the CLIF measures is 
reasonably constant from $89 \%$ in 2010 to $0.91 \%$ in 2014 .

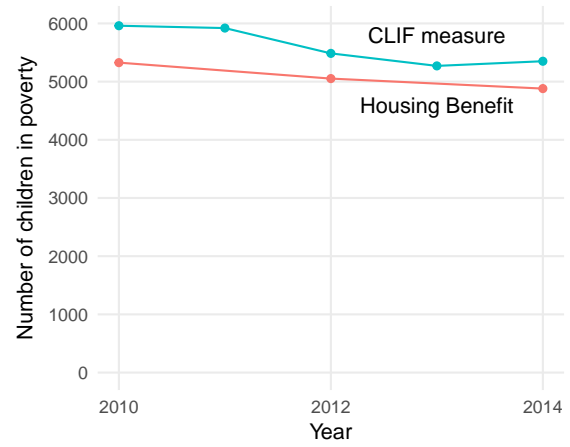

Figure 2: Numbers of children in poverty in Oxford 2010-2014, CLIF and HB measures

The HB and IDID estimates are highly correlated at LSOA level, with $R^{2}$ values ranging from 0.87 for older people to 0.98 for children. Figure 3 plots the estimates of the number of individuals living in families below the poverty line from the August 2012 IDID estimate against the HB estimate, for each of the 83 Lower Super Output Areas in Oxford and by age group. The estimates show a very close correlation across all age groups but particularly for children and working age people.
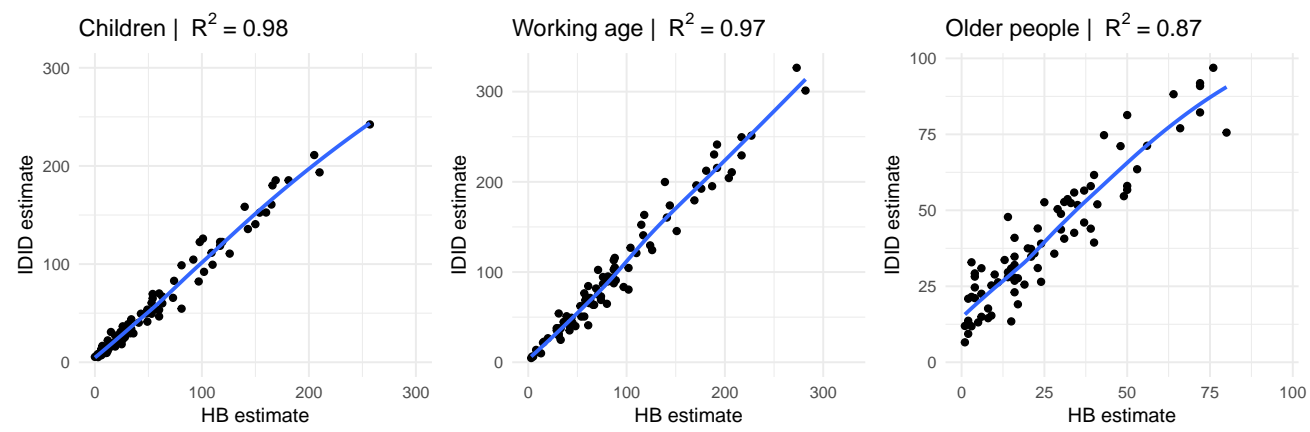

Figure 3: Numbers in poverty by age group for Oxford LSOAs 2012, ID income domain vs housing benefit. Lines show smoothed means

This analysis establishes that the housing benefit estimates are highly correlated with the official estimates at small area level, resulting in very similar spatial distributions of poverty. They have much higher coverage of working age adults and children than of older, pensionable age adults. Given that the HB estimate excludes poor families who own their homes the coverage and correlation is higher than might be expected. This is probably a consequence of the relatively low take-up of means-tested benefits by poor families who own their own home, but possibly also a result of the large private rented sector in the study area. This is discussed further in section 5.1. 


\subsection{Turnover rates of poor families in Oxford 2010-2014}

Having validated that the housing benefit estimates provide a similar picture of income poverty to the official estimates, the remaining analysis focuses solely on the longitudinal housing benefit data to explore how it can be used to improve our understanding of poverty in small areas. The aggregate change in number of poor housing benefit families 2010-2014 is first explored. Poverty turnover rates by family type are examined, and a Sankey diagram is employed to explore the status of families leaving poverty. Logistic regression analysis is used to identify the factors associated with leaving the population of poor families in Oxford.

In 2010 there were 10,690 families in Oxford claiming housing benefit, 8,820 who were income poor according to the method in section 3.6 - comprising $83 \%$ of the total. In 2014 there were 10,840 families claiming housing benefit, 8,190 who were poor - $76 \%$ of the total. Over the period the total number of poor housing benefit families therefore fell by $7 \%$. Figure 4 shows that the largest absolute fall was amongst single working age people, but proportionately the largest falls were observed amongst lone parents (15\%) and couple pensioners (28\%). The fall in poor lone parent families was partly offset by a rise in poor couple parent families of $10 \%$.

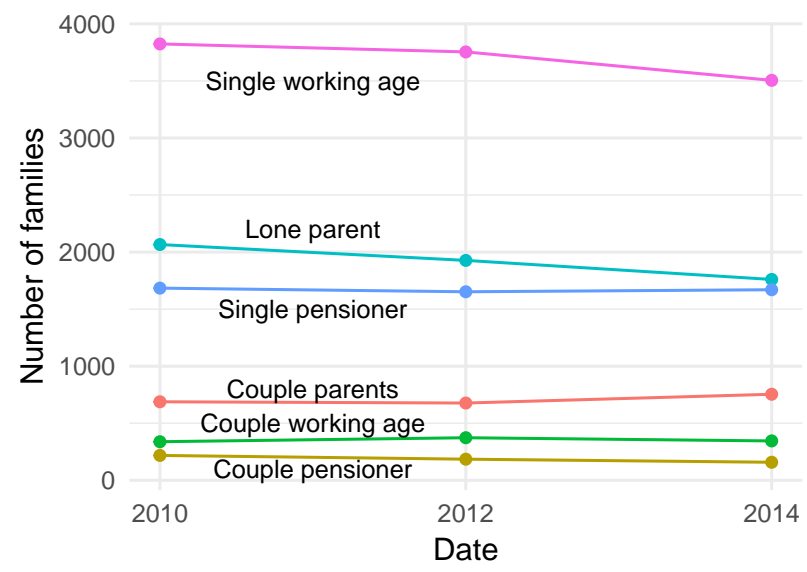

Figure 4: Number of housing benefit families in poverty, Oxford 2010-2014

Linking housing benefit over time enables a study of the dynamics underpinning these cross-sectional, aggregate measures of poverty. Table 2 shows an initial analysis of these dynamics by family type in Oxford. The first column ('In poverty 2010') shows the number of housing benefit families in income poverty in 2010 across the whole of the city. The second and third columns show the number of these families who were still poor in 2012 ('Still in poverty 2012') and 2014 ('Still in poverty 
2014'). The fourth column presents a persistence rate over the period 2010-2014 - defined here as the proportion of the 2010 poor housing benefit families who were still poor and in Oxford in 2014 . The fifth columns introduces the principal measure of poverty dynamics used in this paper - the poverty turnover rate, which is defined as the proportion of families at one time point who were no longer poor families in this geographic locality at a later time point (here, 2010 to 2014). It is therefore also 100 minus the poverty persistence rate for the same period.

Table 2: Poverty persistence and turnover 2010-2014, people

in housing benefit families, Oxford

Poverty

Turnover

Rate

Family type In poverty Still in $\quad$ Still in Persistence rate 2010-2014

$2010 \quad 2010$ poverty 2012 poverty $2014 \quad 2010-2014(\%)$

$\begin{array}{llllll}\text { Couple } & 220 & 180 & 150 & 69.3 & 30.7\end{array}$

pensioner

Couple

340

260

230

67.5

32.5

working age

Single

1,680

1,320

1,050

62.4

37.6

pensioner

Single

3,820

2,590

2,120

55.4

44.6

working age

Lone parent

2,070

1,420

1,020

49.6

50.4

Couple

690

440

330

48.1

51.9

parents

All families

8,820

6,200

4,900

55.6

44.4 
Turnover rates are lower for older families - working age couples without children, couple pensioner and single pensioner families - where around two-thirds of families who were poor in 2010 were still in 2014. Persistence rates are lower for younger families - single working age, lone parents and couple parents - where only half of the families who were poor in 2010 were still poor in 2014. Over a four-year period, there was considerable turnover in the population of poor housing benefit families in Oxford.

Jenkins (2011) (p225) calculated annual poverty exit rates for a similar set of household types over the period 1999-2005 using data from the British Household Panel Survey. The pattern of exit rates has some similarity to the turnover rates observed in Table 2 in that pensionable-age households had the lowest exit rates and couples with children had the highest exit rates. However Jenkins found lower exit rates for lone parent compared to couple parent families, whereas this study shows little difference between them. It is possible that the difference between the two studies is explained by differences in residential mobility rates. There have been changes in Income Support eligibility for lone parents since Jenkins' study which may also have affected exit rates - further discussion of this is included in section 5.1.

The transitions of families - changes in income status over time, and flows on and off housing benefit - can be inspected visually by means of the Sankey diagram in Figure 5. This diagram can be thought of as a series of stacked bar charts for different points in time, connected by lines which show the flow of families from one status to another between time periods. Poor housing families are shown at the bottom, 'near poor' families (income between $60 \%$ and $80 \%$ median) are the second category, then 'not poor' families (income greater than $80 \%$ median income). The top of the diagram is obscured, representing the unobserved population who are not claiming housing benefit in Oxford. Claimants flow in and out of this population, but its total size is unknown (potentially representing the rest of the UK population). The width of the lines between points is proportional to the number of families changing or maintaining their status between time points (2010 to 2012 to 2014, left to right).

The largest flows in and out of poverty in the Sankey chart are of families beginning and ending a housing benefit claim. The diagram also shows that the number of 'near poor' families nearly doubled from 770 in 2012 to 1,490 in 2014 as a result of a flow of families who were 'not poor' moving to the 'near poor' group between 2012 and 2014. This means that a growing number of 
housing benefit families had incomes which did not keep pace with median income growth over this period.

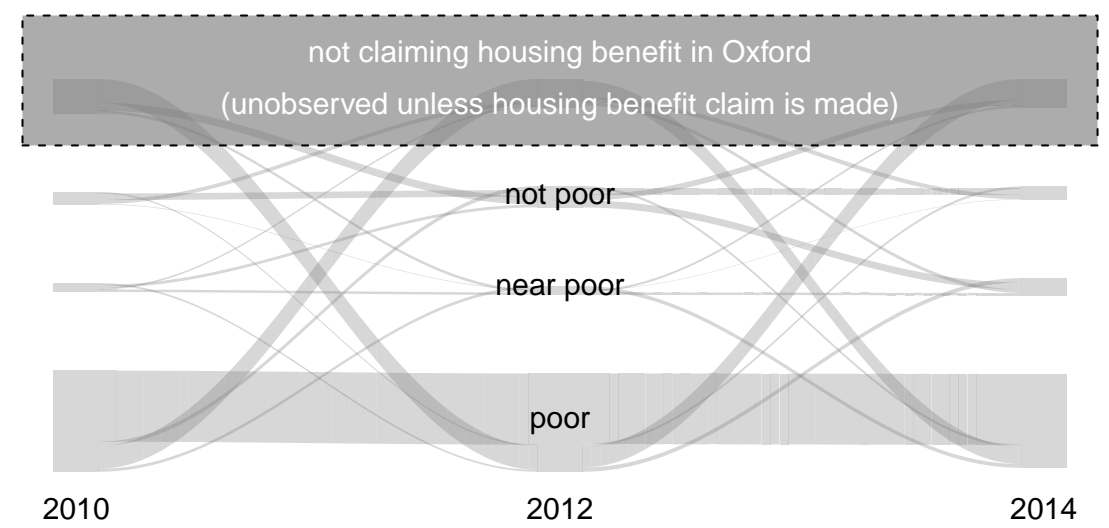

Figure 5: Sankey diagram showing all Oxford families claiming housing benefit in 2010, 2012 and/or 2014; changes in income status and flows on/off housing benefit are shown

The aggregate rates of poverty turnover by family type in Table 2 may partly reflect the composition of these different groups in terms of other factors that are associated with poverty exit and/or residential mobility. In the following analysis, logistic regression is used to explore the association of characteristics recorded in the housing benefit data (the explanatory variables) with the probability of leaving the population of poor Oxford housing benefit families 2010-2014 (the outcome variable).

The explanatory variables included in the logistic regression are: tenancy, with higher rates of residential mobility being expected amongst private sector tenants; type of 'passport' benefit received, which may be related to the likelihood of gaining employment and therefore exiting poverty; family type, which is associated with poverty exit and residential mobility; gender, which is associated with residential mobility (Beatty et al. 2009); and employment in the family, which is associated with poverty exit (see Jenkins (2011) and Champion et al. (1998) for associations of these factors with poverty exit and residential mobility respectively).

The first column of Table 3 shows the results from this logistic regression with main effects considered only. The second column is a more complex model that includes interactions between 'passport' benefit and tenancy, 'passport' benefit and family type, and tenancy and family type. Introducing interactions between these categorical variables introduces another 38 coefficients. Only a few of these were found to be statistically significant in the model, and so for brevity only these are reported in Table 3 . In the text that follows, statistically significant results from the second model 
are discussed.

Amongst families poor in 2010, a higher probability of leaving the population of poor HB families and conversely a lower probability of poverty persistence - was associated with living in a privately rented home, claiming a work-related welfare benefit, being a lone parent, having a male main claimant and having an adult in employment.

By tenancy, social tenants were less likely to leave the city's population of poor housing benefit families than private tenants. Differences in residential mobility would lead us to expect this result: social tenancies tend to be 'tenancies for life' whereas private rented tenants have very little security of tenure. Families in social housing may also be less likely to escape poverty by raising their incomes. Social tenancies are offered to families in highest social need and many are therefore likely to have greater barriers to raising their incomes.

By benefit claimed, lower turnover rates were predicted by families claiming Income Support or Pension Credit (Guarantee). The latter is claimed by low income pensionable age people, who are less likely to seek work and see their income rise. The highest turnover rates were predicted for claimants of income-based Jobseeker's Allowance (JSA(IB)) - an unemployment benefit. Statistics from the Department for Work \& Pensions (via www.nomisweb.co.uk) show that the number of people claiming JSA declined from 2,550 in August 2010 to 1,040 in August 2014. Although eligibility criteria also altered over this period, some of this fall was also likely to due to rising employment levels, suggesting a rise in flows out of poverty due to finding work (for national evidence see Belfield et al. (2016)).

The only significant association amongst family types was for lone parents, who were more likely than couple parents to leave the local population of poor families. This is mediated by the interaction terms in the second model, which indicate that this effect is strongest for lone parents claiming Income Support. The potential for this finding to be driven by recent changes in Income Support eligibility is explored in section 5.1 .

This analysis demonstrates that, underlying a relatively static headline cross-sectional figure for the number of individuals living in families below the poverty line, there was considerable turnover in that population. Around half the population of poor working age families turned over in the four year period 2010-2014, and around a third of pensionable age families. These relatively high levels 
Table 3: Logistic regression predicting exit from the population of poor Oxford HB families 2010-2014 - model coefficients with 95 per cent confidence intervals

\begin{tabular}{|c|c|c|}
\hline & Main effects & Main effects plus interactions \\
\hline Constant & $\begin{array}{c}0.13 \\
{[-0.15 ; 0.42]}\end{array}$ & $\begin{array}{c}-0.47 \\
{[-0.97 ; 0.04]}\end{array}$ \\
\hline \multicolumn{3}{|l|}{ Tenancy (reference: Private sector) } \\
\hline Social rented & $\begin{array}{c}-\mathbf{0 . 8 6}^{*} \\
{[-0.96 ;-0.75]}\end{array}$ & $\begin{array}{c}-\mathbf{0 . 5 5 *} \\
{[-0.95 ;-0.16]}\end{array}$ \\
\hline Other & $\begin{array}{c}-\mathbf{0 . 3 3}^{*} \\
{[-0.65 ;-0.00]}\end{array}$ & $\begin{array}{c}-0.15 \\
{[-2.34 ; 2.05]}\end{array}$ \\
\hline \multicolumn{3}{|l|}{ Benefit (ref: Income Support) } \\
\hline Pension Credit (GC) & $\begin{array}{c}-0.09 \\
{[-0.27 ; 0.09]}\end{array}$ & $\begin{array}{c}-1.58^{*} \\
{[-3.11 ;-0.05]}\end{array}$ \\
\hline JSA (IB) & $\begin{array}{c}\mathbf{0 . 7 8}^{*} \\
{[0.63 ; 0.92]}\end{array}$ & $\begin{array}{c}\mathbf{1 . 5 1}^{*} \\
{[1.04 ; 1.98]}\end{array}$ \\
\hline No other benefit & $\begin{array}{c}\mathbf{0 . 5 7 ^ { * }} \\
{[0.42 ; 0.71]}\end{array}$ & $\begin{array}{c}1.08^{*} \\
{[0.57 ; 1.59]}\end{array}$ \\
\hline ESA (IB) & $\begin{array}{c}\mathbf{0 . 3 7}^{*} \\
{[0.15 ; 0.59]}\end{array}$ & $\begin{array}{c}0.75 \\
{[-0.00 ; 1.50]}\end{array}$ \\
\hline \multicolumn{3}{|l|}{ Family type (ref: Couple parents) } \\
\hline Couple, pensioners & $\begin{array}{c}-0.09 \\
{[-0.45 ; 0.27]}\end{array}$ & $\begin{array}{c}-0.35 \\
{[-3.09 ; 2.40]}\end{array}$ \\
\hline Couple, working age & $\begin{array}{c}-\mathbf{0 . 3 7 ^ { * }} \\
{[-0.67 ;-0.07]}\end{array}$ & $\begin{array}{c}-0.53 \\
{[-1.41 ; 0.35]}\end{array}$ \\
\hline Lone parent & $\begin{array}{c}\mathbf{0 . 5 2}^{*} \\
{[0.33 ; 0.72]}\end{array}$ & $\begin{array}{c}\mathbf{0 . 9 4}^{*} \\
{[0.49 ; 1.40]}\end{array}$ \\
\hline Single pensioner & $\begin{array}{c}\mathbf{0 . 4 2}^{*} \\
{[0.19 ; 0.65]}\end{array}$ & $\begin{array}{c}0.25 \\
{[-0.79 ; 1.28]}\end{array}$ \\
\hline Single working age & $\begin{array}{c}-0.05 \\
{[-0.23 ; 0.13]}\end{array}$ & $\begin{array}{c}0.38 \\
{[-0.06 ; 0.81]}\end{array}$ \\
\hline \multicolumn{3}{|l|}{ Gender (ref: Female) } \\
\hline Male & $\begin{array}{c}\mathbf{0 . 1 5}^{*} \\
{[0.05 ; 0.26]}\end{array}$ & $\begin{array}{c}\mathbf{0 . 1 8}^{*} \\
{[0.07 ; 0.28]}\end{array}$ \\
\hline \multicolumn{3}{|l|}{ Employment (ref: Employed) } \\
\hline Unemployed & $\begin{array}{c}-\mathbf{0 . 4 2} \\
{[-0.66 ;-0.18]}\end{array}$ & $\begin{array}{c}-\mathbf{0 . 3 1}^{*} \\
{[-0.57 ;-0.05]}\end{array}$ \\
\hline \multicolumn{3}{|l|}{ Interactions } \\
\hline Social rented $\mathrm{x}$ no other benefit & & $\begin{array}{c}-\mathbf{0 . 3 4}^{*} \\
{[-0.63 ;-0.04]}\end{array}$ \\
\hline $\mathrm{JSA}(\mathrm{IB}) \mathrm{x}$ lone parent & & $\begin{array}{c}-1.39^{*} \\
{[-1.92 ;-0.85]}\end{array}$ \\
\hline No other benefit $\mathrm{x}$ lone parent & & $\begin{array}{c}-\mathbf{0 . 5 9}^{*} \\
{[-1.13 ;-0.05]}\end{array}$ \\
\hline ESA (IB) $x$ lone parent & & $\begin{array}{c}-1.55^{*} \\
{[-2.39 ;-0.70]}\end{array}$ \\
\hline JSA (IB) $x$ single working age & & $\begin{array}{c}-\mathbf{0 . 5 4} \\
{[-1.00 ;-0.08]}\end{array}$ \\
\hline Social rented $\mathrm{x}$ single working age & & $\begin{array}{c}-\mathbf{0 . 4 1}^{*} \\
{[-0.79 ;-0.02]}\end{array}$ \\
\hline AIC & 11220.62 & 11145.33 \\
\hline BIC & 11319.80 & 11492.47 \\
\hline Log Likelihood & -5596.31 & -5523.66 \\
\hline Deviance & 11192.62 & 11047.33 \\
\hline Num. obs. & 8818 & 8818 \\
\hline
\end{tabular}


of turnover have potential implications for the way that local authorities and other organisations seek to improve the circumstances of low income families in their areas. These turnover rates may also differ by neighbourhood, which could lend itself to variation in the policies which are employed - a question to which this paper now turns.

\subsection{The spatial variation in local poverty dynamics}

This subsection examines the question of whether there is variation in poverty turnover rates within the city by neighbourhood area. In this section, the poverty turnover rates are a measure of the churn of poor families within individual neighbourhood areas. Consequently, higher turnover rates are expected than those observed in section 4.2 as moves between different neighbourhoods within the city also contribute. Using this method the average poverty turnover rate for Oxford is $53 \%$, compared to $44 \%$ in Table 2. First, a funnel plot is used to identify areas which have significantly high or low turnover rates compared to the Oxford average; second, regression analysis is used to explore the area factors associated with these differential rates.

Figure 6 plots poverty turnover rates calculated analogously to Table 2. The denominator of the rate is the number of housing benefit families poor in the neighbourhood in 2010; the numerator is the number of housing benefit families still poor and still living in the neighbourhood in 2014 . The solid line shows the Oxford average whilst the curved lines forming the funnel show the region within which $95 \%$ of the rates would fall if the underlying turnover rates were all equal to the city average. The expected variance of the turnover rate varies with the number of families poor in 2010 as this is the effective sample size for estimation.

A significant proportion of the estimated poverty turnover rates fall outside the lines on the funnel plot - and many more than the four (83 LSOAs x 5\%) that would be expected from the assumption of equal underlying turnover rates. Therefore there is statistically significant variation in the poverty turnover rates measured at neighbourhood level in Oxford between 2010 and 2014.

The map in Figure 1 plots the high and low turnover rates on a map of Oxford by LSOA ${ }^{2}$. With local knowledge, an inspection of this map reveals that the lowest turnover rates are areas with high concentrations of social rented housing, the high turnover rate areas being areas of high private

\footnotetext{
${ }^{2}$ An interactive version of Figure 1 is available at https://mfransham.github.io/2017-09-Oxf-pov-turnover-map/.
} 


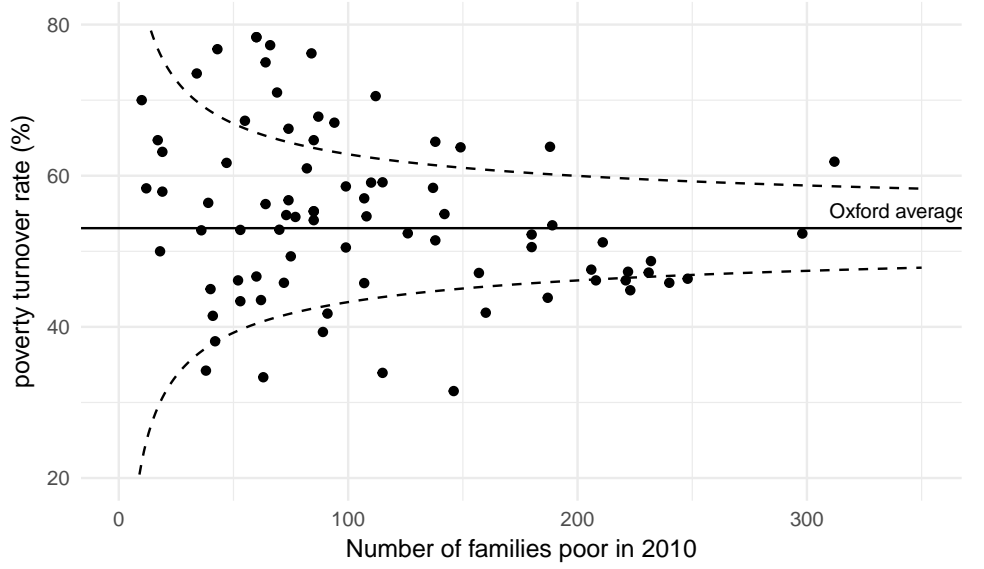

Figure 6: Funnel plot of poverty turnover rates by LSOA, 2010-2014 with 95 per cent confidence intervals

rented housing.

In order to confirm whether the differential rates of turnover are driven by the composition of housing benefit families in those areas, a weighted linear regression was conducted with poverty turnover rate as the dependent variable. Observations were weighted by the total number of poor families in 2010. The initial model contained the same main effects as the individual-level model in section 4.2 (expressed as proportions of the population in the area) and was reduced by backward stepwise selection.

The final model in table 4 is a rather simpler model than the individual-level model in section 4.2 . Around $60 \%$ of the variation in LSOA turnover rates is explained by the private/social rented split of housing benefit families in the area and the type of benefit claimed by housing benefit families (split between Income Support, Pension Credit and JSA/ESA/no other benefit). A 40 percentage point higher proportion of social housing is associated with around 10 percentage point lower turnover rates; a 40 percentage point higher proportion of families claiming JSA, ESA or no other benefit is associated with around 10 percentage point higher turnover rates. Regression diagnostics (not shown) indicate that an area in the city centre is an outlier for which the model does not fit well. This is an area with a number of temporary hostels for single homeless people resulting in a high turnover rate in an area with a large amount of social rented housing.

The high poverty turnover rates discovered above raises a question - is this simply due to the migration of persistently poor families within the city? This factor explains only a small proportion of 
Table 4: Linear weighted regression predicting poverty turnover rate by LSOA

\begin{tabular}{lc}
\hline Constant & $\mathbf{0 . 6 6}$ \\
& {$[0.52 ; 0.80]$} \\
Social housing tenants & $-\mathbf{0 . 2 4}$ \\
& {$[-0.32 ;-0.16]$} \\
Pension Credit claimants & $-\mathbf{0 . 2 7}$ \\
& {$[-0.44 ;-0.11]$} \\
Claiming JSA, ESA or no other benefit & $\mathbf{0 . 2 6}$ \\
& {$[0.04 ; 0.48]$} \\
\hline $\mathrm{R}^{2}$ & 0.62 \\
Adj. $\mathrm{R}^{2}$ & 0.61 \\
Num. obs. & 83 \\
RMSE & 0.64 \\
\hline${ }^{*} 0$ outside the confidence interval &
\end{tabular}

the picture. Over the study period 4,680 poor Oxford housing benefit families left the neighbourhood population of poor families either through leaving poverty or leaving the area. Of these 1,130 were due to persistently poor families moving to another LSOA - accounting for just under a quarter of the neighbourhood-level poverty turnover rate.

This analysis reveals a high rate of turnover among the population of poor families in all Oxford LSOAs, driven by income mobility out of poverty and residential mobility out of the area. The highest poverty turnover rates were found in areas with a high proportion of private renting. However, even in the area with the lowest turnover rate one-third of poor families in 2010 were not among that area's population of poor families in 2014, and for most areas it was around one half. These high rates of turnover underly a relative static geography of poverty presented by the official cross-sectional estimates.

\section{Discussion}

\subsection{Summary and policy implications}

As set out in section 3.1, this study has: (i) explored whether housing benefit can be used to create an income poverty indicator that is consistent with official small area estimates; (ii) described the level of turnover in the population of poor families covered by the indicator and the characteristics associated with turnover; and (iii) explored the sub-city variation in poverty turnover rates. Section 4.1 found that the numbers of individuals estimated by the HB indicator to be living in families below the poverty line was similar in magnitude to the official estimates for children and working 
age people, but significantly smaller for older people. It also found that the HB indicator described a very similar spatial distribution across LSOAs to the official estimates.

The similarity of the HB indicator and official estimates is surprising, given that around $40 \%$ of poor working age families own their home and are therefore excluded from the housing benefit indicator. This is probably a consequence of two factors. First, it is an empirical reminder of a finding of Bradshaw and Richardson (2007) when exploring spatial variation in the take-up of means-tested benefits: compared to renting families, owner-occupiers substantially underclaim the benefits to which they are entitled. This means official estimates based on means-tested benefit data that ostensibly include owner-occupiers in estimates of the prevalence of income poverty in fact substantially exclude them. This is also a limitation of the housing benefit indicator used in this study, but one could argue that at least owner-occupiers are transparently excluded from its scope. Second, this could also be an artefact of the large private rented sector in the study area, which may mean that owner-occupiers make up a smaller proportion of poor families than average.

Section 4.2 found that of Oxford housing benefit families poor in 2010, $44 \%$ were no longer amongst the population of poor Oxford families in 2014. By family type, higher turnover rates were observed amongst families with children, lower turnover rates amongst pensionable age families. Analysed at individual level, a higher probability of leaving the population of poor HB families was associated with living in a privately rented home, claiming a work-related welfare benefit, being a lone parent, having a male main claimant and having an adult in employment.

The existing literature does not offer (to the author's knowledge) any direct comparison to the findings in this paper. However, they are broadly in line with what one might expect from other studies. Jenkins (2011) has found similar patterns of poverty exit to those described in section 4.2. Noble et al. (1998) found that $43 \%$ of Income Support claimants at the start of a four-year period had a claim at the end of it. Barnes et al. (2011), though focused on high workless areas - not a definition that would apply to any Oxford neighbourhoods - found that $25 \%$ of persistently workless families moved over a four-year period. Private renting is associated with higher residential mobility (Champion et al. 1998) and employment within the family is associated with higher poverty exit (Jenkins 2011), both therefore predicting the higher poverty turnover rates associated with these characteristics.

There are four explanations for flows out of the population of poor families - income mobility out 
of poverty, residential mobility out of the area, persistently poor families ceasing housing benefit claims and mortality of housing benefit claimants. The interpretation of this study rests on the fact that these first two flows are the most important, and the second two are relatively unimportant. The findings would be compromised if a significant proportion of the poverty turnover observed was attributable to the third of these flows, poor families remaining poor and in Oxford but leaving housing benefit. One possible cause of this could be declining claims rates because of the benefit reforms described in section 3.2. If this had been the case a decline in national take-up rates would be expected, but the available evidence suggests this has not occurred. The latest estimates of benefit take-up suggest that $76 \%$ of eligible working-age families claimed housing benefit in 2014/15, with no statistically significant change since 2009/10 (DWP 2016a).

Another cause for this kind of flow could be workless housing benefit families ceasing their claim upon gaining employment, even if their income is still low enough to be eligible. There is more evidence for this: housing benefit take-up rates amongst eligible workless families were $95 \%$ in 2012/13, but only 55\% amongst eligible in-work families. An order-of-magnitude approximation suggests that this phenomenon is likely to account for only a small proportion of the flows of poor families off housing benefit. Among the 7,000 working age families poor in 2010 there were just under 4,000 families who were still poor in 2014. A little under 300 of these 4,000 families had gained employment by 2014 but still had incomes below the poverty line (and were still claiming housing benefit). Based on the $50 \%$ take-up figure amongst in-work families we might expect a similar number of persistently poor families to have gained employment but no longer be claiming housing benefit. If so, this would amount to just 300 of the 3,000 observed flows off housing benefit.

The fourth of these flows, mortality, is most significant for single-person older families; approximately $16 \%$ of over $65 \mathrm{~s}$ in Oxford would be expected to die over a four-year period (author's calculation from ONS mortality data).

It is therefore argued that flows attributable to income mobility and residential mobility are the dominant cause of the observed poverty turnover patterns. However the interrelation of these two processes cannot be disentangled, so the observation that - for example - around half of poor Oxford families with children 'turned over' in a four-year period requires careful interpretation. Any policy implications to be drawn require similar care.

The flows out of the population of poor Oxford housing benefit families could be one of three types - 
and imply three possible 'counter-flows' of new arrivals into the poor population. Two of these flows are associated with poverty exit - a family raises their income out of poverty, either staying in the area or leaving it. The third of these flows is persistently poor families leaving an area - potentially combining persistent poverty with loss of social networks, employment opportunities etc. (Beatty et al. 2009).

Without observing the destination of these off-flows it is difficult to qualitatively evaluate the high levels of poverty turnover. To the extent that these flows are indicative of high levels of poverty exit - as highlighted by Stephen Jenkins' research - it reminds anti-poverty policymakers to focus as much on poverty (re-)entry as focusing on getting people out of poverty. To the extent that it reflects high levels of residential mobility amongst persistently poor families, it points to the need to improve security of housing tenure to facilitate the development and maintenance of social networks.

Section 4.2 finds that lone parents claiming Income Support (IS) had a raised probability of leaving the population of poor housing benefit families. Over the period of this study Income Support for lone parents has been subject to increasing eligibility restrictions. In 2008 it was restricted to lone parents whose youngest child was under 12 years, to under 7 years in 2010, and in 2011 to under 5 years. Lone parents no longer eligible for Income Support but not employed full-time are moved on to Jobseeker's Allowance and required to actively seek work as a condition of receiving the benefit. National evaluation showed that whilst the majority of lone parents who lost eligibility for Income Support in 2011 moved on to a different out-of-work benefit, a quarter found employment (Coleman and Riley 2012), though there was no counterfactual estimate of the number who would have gained employment without the policy change. The higher poverty turnover rate for lone parents claiming Income Support could be explained by increased employment amongst those lone parents who lost eligibility to IS during this period. This was certainly the stated objective of the policy. It could also be due to increased residential mobility amongst this group, perhaps caused by withdrawal of means-tested benefits in cases where lone parents were unable or did not wish to search for work as required. Again, without observing the destination of these off-flows (and providing counterfactual estimates) it is difficult to safely interpret this finding.

Section 4.3 shows that there are neighbourhood areas with statistically significantly low and high poverty turnover rates, ranging from $32 \%$ to $78 \%$. The variation in rates is substantially explained by the composition of poor housing benefit families in each area, namely the split between private 
and social rented housing, and the types of 'passport' benefit claimed. Areas with higher proportions of families in social rented housing are associated with lower poverty turnover rates.

During the New Labour years 1997-2010 substantial amounts of funding were directed towards the 'most deprived' areas of England (Lupton et al. 2013). In a spirit of 'new localism' area policy is now locally determined (Lupton and Fitzgerald 2015) and although most central government funding has now ceased, some local bodies continue to employ area-based initiatives to tackle local deprivation. In Oxford such work has and continues to be focused on those social housing estates which feature among the $20 \%$ most deprived areas according to the English Indices of Deprivation. Despite loss of social housing stock to the 'right to buy' initiative, these estates still have high concentrations of social housing and consequently have among the lowest poverty turnover rates in the city. This research provides empirical evidence to the designers of area-based initiatives about the level of turnover in the local population of poor families. This means that for many families, support provided by such initiatives may be relatively short-term and need to be designed accordingly. There will also remain a minority of stable residents who are persistently or chronically poor over long periods, for whom support may need to be more intensive and/or longer term.

\section{$5.2 \quad$ Limitations}

As noted in section 3.4, the study area is an unusual local authority area, with a very high student population, poor housing affordability and a large private rented sector. This begs the question to what extent this method and the substantive findings are generalisable to other areas.

Section 4.1 found that, for children and working age people in particular, the HB indicator resulted in similar coverage and spatial distribution to the official estimates. This was surprising given the exclusion of owner-occupying poor families from the indicator. Oxford has a very large private rented sector and poor housing affordability; these two factors combined may mean that (i) renters account for a higher-than-average proportion of poor families, and (ii) in the face of high housing costs, low income families are more likely to claim the housing benefit to which they are entitled. However it is plausible that this method would also work in areas with cheaper housing and a smaller private rented sector, given the large proportion of renting families who do claim housing benefit (whether poor or not) and the low coverage of owner-occupiers by official estimates. It is an empirical question whether a housing benefit indicator in an area with a smaller private rented 
sector would be so similar to the official estimates.

A related question is how housing unaffordability and the large rental sector in Oxford might have influenced the substantive findings. The poverty turnover rates observed in this study are in line with what might be expected from previous studies in terms of their order of magnitude. One might expect the turnover rates in Oxford to be elevated due to high housing affordability pushing low income families out of the city, and a larger than average private rented sector would raise residential mobility rates. This would be interesting to explore with a national dataset (see section $5.3)$.

This study replicates the official estimates' method for classifying the poverty status of families, which employs a 'before housing costs' definition (section 3.6). An 'after housing costs' definition might raise the overall estimates of poverty in Oxford, given the relatively high housing costs. It may also increase poverty depth, the gap between family income and the poverty line. Under such a measure the HB indicator may reveal lower levels of turnover, as those families raising their income from 'poor' to 'near poor' are no longer classified as escaping poverty.

The high turnover rates revealed in this study beg another question: are those people who are no longer poor likely to experience another spell of poverty soon afterwards? The short time period and limited data points in this study mean that this question cannot be answered. In his review of poverty dynamics evidence, Jenkins (2011) found that (looking at those currently not poor) poverty re-entry rates for those who had been poor the year before were $35 \%$, compared to an entry rate of $6 \%$ for those who were not poor the year before (p225). Thus poverty re-entry and recurrence is an important part of the picture when understanding poverty dynamics.

\subsection{Further work}

Three pieces of further work are identified here: extending the current method over a wider geographic area; using a wider range of administrative data sources; and utilising household panel survey data.

As noted above, the interpretation of findings is limited by the fact that off-flows could be due to residential mobility or income mobility, and the two cannot be disentangled. Extending the geographic scope of the dataset would mean that residential mobility within the population of 
housing benefit families could be observed, and by implication income mobility could be inferred. Given that most residential moves are over short distances (Fielding 2012, p3), a dataset with coverage into the four local authority areas surrounding Oxford may be able to achieve this. A dataset with national coverage would provide yet more robust estimates of the relative importance of income mobility and residential mobility. This would also enable comparison of poverty turnover rates within and between local labour market areas.

In this study, poor families are only observable whilst they are claiming housing benefit. Other studies, including Barnes et al. (2011), have used a wider range of benefit and tax data to ensure a broader coverage of observations. A greater depth of information could potentially be achieved by linking the housing benefit data to other local sources of information such as council tax data to observe residential mobility rates. The Office for National Statistics have recently produced small area experimental estimates of income based upon administrative records from welfare benefits and tax payments (Office for National Statistics 2016b). These have the benefit of capturing a broader population including those who are not claiming any welfare benefits, though some people are still likely to be hidden from these data sources. As this develops, it may be possible to utilise these data sources for the longitudinal study of poverty within small areas. The introduction of Universal Credit may offer research opportunities insofar as it will cover a broader population than any one of the benefits currently in place, and will cover both in-work and out-of-work benefits. Universal Credit has suffered long delays in its introduction however, so the timescale for the realisation of this potential is unpredictable.

Finally, panel data from the UK Household Longitudinal Study could be used, in a similar way to Jenkins (2011), to unpick the relative contributions of income mobility and residential mobility in driving poverty turnover rates. It could also potentially be used to explore local correlates of these rates including housing affordability and labour market conditions.

\section{Conclusion}

This study has explored the use of longitudinally-linked housing benefit data to measure poverty dynamics in the neighbourhoods of an English local authority area. The poverty turnover rate measure for working age families, which covers low income families who rent their homes and claim 
state support for their housing costs, closely correlates with and has similar coverage to official small area estimates which use a wider range of means-tested benefits. The measure indicates a high turnover of poor families within the four year period 2010-2014, with a higher probability of turnover associated with living in a privately rented home, claiming a work-related welfare benefit, being a lone parent and having an adult in employment. The poverty turnover rate is able to identify neighbourhoods with higher and lower turnover rates than the average for the city. This is primarily due to the differing composition of families by tenure within those areas - high turnover rate areas having high concentrations of private rented housing. The higher turnover rates associated with families in private rented housing could be a function of higher rates of poverty exit and/or higher rates of residential mobility.

In many places the geography of poverty is relatively stable over time - the areas which have high concentrations of poor families tend to be unchanging from one decade to the next. The stigmatising inference that this identifies the location of a persistently poor, welfare-dependent underclass is the spatial manifestation of the myth which John Hills has argued against in his book Good Times, Bad Times: The Welfare Myth of Them and Us (Hills 2014b). To use the terms of Tunstall (2016) some - perhaps many - neighbourhoods which are apparently slothful in the rate at which cross-sectional poverty rates change are, in fact, highly dynamic under the surface. The high turnover rates observed in this study speak not of a static population of poor families, but of people moving in and out of poverty and in and out of poor areas over time.

\section{References}

Addison, T., Hulme, D., \& Kanbur, R. (2009). Poverty dynamics: measurement and understanding from an interdisciplinary perspective. In T. Addison, D. Hulme, \& R. Kanbur (Eds.), Poverty Dynamics: Interdisciplinary Perspectives. Oxford: Oxford University Press.

Anderson, B. (2007). Creating Small Area Income Estimates for England: spatial microsimulation modelling. London: Department for Communities; Local Government.

Bailey, N., \& Livingston, M. (2007). Population Turnover and Area Deprivation. York: Joseph 
Rowntree Foundation.

Barnes, H., Garratt, E., McLennan, D., \& Noble, M. (2011). Understanding the worklessness dynamics and characteristics of deprived areas. London: Department for Work \& Pensions.

Beatty, C., Lawless, P., Pearson, S., \& Wilson, I. (2009). Residential mobility and outcome change in deprived areas. London: Department for Communities \& Local Government.

Belfield, C., Cribb, J., Hood, A., \& Joyce, R. (2016). Living Standards, Poverty and Inequality in the UK: 2016. London: Institute for Fiscal Studies.

Bossert, W., Chakravarty, S. R., \& Ambrosio, C. D. (2012). Poverty and time. Journal of Economic Inequality, 10, 145-162.

Bradshaw, J., \& Richardson, D. (2007). Spatial Variations in the Take-Up of Means-Tested Benefits. London: Department for Communities \& Local Government.

Carstairs, V., \& Morris, R. (1990). Deprivation and health in Scotland. Health Bulletin, 48(4), $162-75$.

Centre for Cities. (2017). Cities Outlook 2017. London: Centre for Cities.

Champion, T., Fotheringham, S., Rees, P., Boyle, P., \& Stillwell, J. (1998). The Determinants Of Migration Flows In England: A Review Of Existing Data And Evidence. Newcastle upon Tyne: University of Newcastle.

Coleman, N., \& Riley, T. (2012). Lone Parent Obligations: following lone parents' journeys from benefits to work. London: Department for Work \& Pensions.

Dorling, D., Rigby, J., Wheeler, B., Ballas, D., Thomas, B., Fahmy, E., et al. (2007). Poverty, Wealth and Place in Britain, 1968-2005. York: Joseph Rowntree Foundation.

DWP. (2010). Households Below Average Income 1994/5 - 2008/9. London: Department for Work \& Pensions.

DWP. (2016a). Income-Related Benefits : Estimates of Take-up 2014/15. London: Department for 
Work \& Pensions.

DWP. (2016b). Households below average income (HBAI) statistics. London: Department for Work \& Pensions.

Fielding, T. (2012). Migration in Britain: Paradoxes of the Present, Prospects for the Future. Cheltenham: Edward Elgar.

Fry, R. (2011). Understanding household income poverty at small area level. Regional Trends, 43, $1-16$.

Gambaro, L., Joshi, H., Lupton, R., Fenton, A., \& Lennon, M. C. (2015). Developing Better Measures of Neighbourhood Characteristics and Change for Use in Studies of Residential Mobility: A Case Study of Britain in the Early 2000s. Applied Spatial Analysis and Policy, 9(4), 569-590.

Gordon, D. (2006). The concept and measurement of poverty. In C. Pantazis, D. Gordon, \& R. Levitas (Eds.), Poverty and Social Exclusion in Britain. Bristol: The Policy Press.

Hills, J. (2014a). The idea that there is a welfare-dependent underclass is wrong. http://blogs.lse. ac.uk/politicsandpolicy/the-welfare-states-surprising-winners/

Hills, J. (2014b). Good Times, Bad Times: The welfare myth of them and us. Bristol: Policy Press.

HMRC. (2014). Children in Low-Income Families Local Measure. London: HM Revenue \& Customs.

Jenkins, S. P. (2011). Changing Fortunes: income mobility and poverty dynamics in Britain. Oxford: Oxford University Press.

Lodge, W. (2015, September). Jaywick ranked most deprived area of England - again.

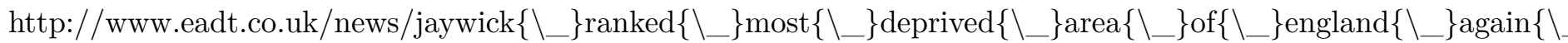
Lupton, R., \& Fitzgerald, A. (2015). The Coalition's record on Area Regeneration and Neighbourhood Renewal 2010-2015. London: London School of Economics; London School of Economics.

Lupton, R., Fenton, A., \& Fitzgerald, A. (2013). Labour's Record on Neighbourhood Renewal in England: Policy, Spending and Outcomes 1997-2010. London: London School of Economics; London 
School of Economics.

Noble, M., Smith, G., \& Cheung, S. Y. (1998). Lone mothers moving in and out of benefit. York: Joseph Rowntree Foundation.

Office for National Statistics. (2016a). Persistent Poverty in the UK and EU: 2014. https://www.ons.gov.uk/peoplepopulationandcommunity/personalandhouseholdfinances/ incomeandwealth/articles/persistentpovertyintheukandeu/2014. Accessed 16 May 2016

Office for National Statistics. (2016b). Research Outputs: Income from PAYE and benefits for tax year ending 2014. https://www.ons.gov.uk/census/censustransformationprogramme/ administrativedatacensusproject/administrativedatacensusresearchoutputs/populationcharacteristics/ researchoutputsincomefrompayeandbenefitsfortaxyearending2014. Accessed 16 December 2016

Oxford City Council. (2015). Child poverty in Oxford. Oxford: Oxford City Council. https://www.oxford.gov.uk/downloads/file/992/child $\left\{\backslash \_\right\}$poverty $\left\{\backslash \_\right\} \operatorname{in}\left\{\backslash \_\right\}$oxford $\left\{\backslash \_\right\}$february $\left\{\backslash \_\right\} 2015$

R Core Team. (2016). R: A language and environment for statistical computing. Vienna: R Foundation for Statistical Computing. https://www.r-project.org/

Robson, B., Lymperopoulou, K., \& Rae, A. (2009). A typology of the functional roles of deprived neighbourhoods. London: Department for Communities \& Local Government.

Smith, G., Noble, M., Annttila, C., Gill, L., Zaidi, A., Wright, G., et al. (2004). The value of linked administrative records for longitudinal analysis (Report to the ESRC National Longitudinal Strategy Committee). Oxford: Department of Social Policy \& Social Work, University of Oxford.

Smith, N., \& Middleton, S. (2007). A review of poverty dynamics research in the UK (pp. 1-122). York: Joseph Rowntree Foundation.

Smith, T., Noble, M., Noble, S., Wright, G., McLennan, D., \& Plunkett, E. (2015a). The English Indices of Deprivation 2015 - Technical Report. London: Department for Communities \& Local Government.

Smith, T., Noble, M., Noble, S., Wright, G., McLennan, D., \& Plunkett, E. (2015b). The English Indices of Deprivation 2015: Research Report. London: Department for Communities \& Local 


\section{Government.}

Tunstall, R. (2016). Are neighbourhoods dynamic or are they slothful? The limited prevalence and extent of change in neighbourhood socio-economic status, and its implications for regeneration policy. Urban Geography, 37(5), 769-784.

Webster, D. (2016). Benefit sanctions have failed: a Comprehensive Review is needed. http://blogs. lse.ac.uk/politicsandpolicy/benefit-sanctions-have-failed-a-comprehensive-review-is-needed/

Weiner, J. (2015). Riverplot: Sankey or ribbon plots. https://CRAN.R-project.org/package= riverplot

Wickham, H., \& Chang, W. (2016). Ggplot2: Create elegant data visualisations using the grammar of graphics. https://CRAN.R-project.org/package=ggplot2

Wickham, H., \& Francois, R. (2016). Dplyr: A grammar of data manipulation. https://CRAN. R-project.org/package $=$ dplyr

Williamson, P. (2015). Small-Area Incomes: Their Spatial Variability and the Relative Efficacy of Proxy, Geodemographic, Imputed and Model-Based Estimates. Applied Spatial Analysis and Policy, 9(4), 463-489. http://link.springer.com/10.1007/s12061-015-9163-1 